\title{
O trabalho do professor sob o ponto de vista dos gestos didáticos
}

\section{The teaching work under the point of view of the didactic gestures}

Eliana Merlin Deganutti de Barros*

Universidade Estadual do Norte do Paraná

Cornélio Procópio - Paraná / Brasil

RESUMO: Este artigo tem como foco o trabalho do professor sob o ponto de vista dos recentes estudos do Interacionismo Sociodiscursivo (tanto no Brasil como no exterior), com enfoque especial para a problemática dos gestos didáticos. Para ilustrar as discussōes teóricas, apresentamos uma análise do primeiro módulo da sequência didática do gênero "carta de reclamação", elaborada e desenvolvida a partir do enfoque colaborativo, num $6^{\circ}$ ano da escola pública, durante o processo do nosso doutoramento. Essa análise foca o trabalho docente, pelo viés dos gestos didáticos (fundadores e específicos) na mobilização da ferramenta "sequência didática".

PALAVRAS-CHAVE: trabalho docente; destos didáticos; sequência didática.

ABSTRACT: This paper focuses on the teaching work under the point of view of the recent studies of Sociodiscursive Interactionism (both in Brazil and abroad), with special focus for the problematic of didactic gestures. To illustrate the theoretical discussions, we present an analysis of the first module of the didactic sequence of the genre "letter of complaint", elaborated and developed from the collaborative focus, in a public school $6^{\circ}$ grade, during the process of our $\mathrm{PhD}$. This analysis focus on the teaching work, by the bias of didactic gestures (founders and specifics) on the mobilization of the tool "didactic sequence".

KEYWORDS: teaching work; didactic gestures; didactic sequence.

\section{Introdução}

Nas últimas décadas, no cenário internacional, as investigações da linguagem em interação nas atividades de trabalho proporcionaram numerosos estudos sobre as mais diversas práticas profissionais (GROSJEAN; LACOSTE, 1999; CLOT, 2007; BULEA, 2010). Recentemente, essas

\footnotetext{
* Doutora em Estudos da Linguagem pela Universidade Estadual de Londrina (UEL). Professora da Universidade Estadual do Norte do Paraná (UENP), campus de Cornélio Procópio. E-mail: edeganutti@hotmail.com / elianamerlin@uenp.edu.br.
} 
investigações da atividade profissional pelo viés das interações linguageiras passaram também a focar o ambiente escolar e "permitiram ressaltar o caráter interativo dos mecanismos de aprendizagem em geral e da apropriação de línguas em particular" (FILLIETTAZ, 2004, p. 203).

No Brasil, pesquisadores do Grupo ALTER, vinculados ao Programa de Estudos Pós-Graduados em Linguística Aplicada e Estudos da Linguagem (LAEL) da PUC/SP, vêm desenvolvendo pesquisas na área da análise da atividade de trabalho (CRISTOVÃO; ABREU-TARDELLI, 2009; MACHADO; LOUSADA; FERREIRA, 2011) a partir dos aportes teóricometodológicos do Interacionismo Sociodiscursivo (doravante, ISD BRONCKART, 2003, 2006, 2008), da Ergonomia da Atividade (AMIGUES, 2004; SAUJAT, 2004, FAÏTA, 2004) e da Clínica da Atividade (CLOT, 2007). Disciplinas essas que têm em comum o fato de assumirem uma "abordagem marxista do trabalho e/ou uma abordagem vigotskiana do desenvolvimento e/ou uma abordagem sócio-discursiva da linguagem" (MACHADO et al., 2009, p. 16). O livro organizado por Cristovão e AbreuTardelli (2009) traz alguns estudos desenvolvidos por esse Grupo, na perspectiva do trabalho do professor.

$\mathrm{Na}$ Universidade Estadual de Londrina (UEL), o Grupo GEMFOR Gêneros Textuais e Mediações Formativas -, coordenado pela Profa. Dra. Elvira Lopes Nascimento, e do qual participei como colaboradora, pesquisadora e formadora, também desenvolve pesquisas com foco na atividade docente. Em conformidade com os postulados que norteiam o Grupo ALTER, esse Grupo também desenvolve pesquisas com foco no trabalho do professor, buscando compreender e clarear a significação e as condições de realização do métier educacional, em uma abordagem sociodiscursiva da linguagem, sob o viés dos gêneros - textuais e/ou da atividade (NASCIMENTO, 2009). Essas pesquisas se propõem a contribuir para as investigaçōes sobre o ensino como trabalho (SAUJAT, 2004), sob a ótica da atividade do professor e das mediações formativo-instrumentais.

Com aportes teórico-metodológicos advindos do Grupo GEMFOR, este texto, recorte de nossa tese de doutoramento ${ }^{1}$ defendida na UEL em 2012,

\footnotetext{
${ }^{1}$ Tese intitulada Gestos de ensinar e de aprender gêneros textuais: a sequência didática como instrumento de mediação, defendida no Programa de Pós-Graduação em de Estudos da Linguagem da Universidade Estadual de Londrina (UEL), sob orientação da Profa. Dra. Elvira Lopes Nascimento. Agradeço à CAPES pela bolsa concedida durante o desenvolvimento da pesquisa.
} 
propõe-se a apresentar a atividade do professor sob a ótica dos gestos didáticos (AEBY-DAGHÉ; DOLZ, 2008), tendo como foco o desenvolvimento de um projeto de produção escrita, fundamentado na metodologia das sequências didáticas (doravante, SD) desenvolvida por pesquisadores filiados ao ISD (SCHNEUWLY; DOLZ, 2004).

Pata estruturar este artigo, trazemos, primeiramente, um resumo do contexto da pesquisa colaborativo-intervencionista, a qual nos serviu de fonte de dados para a investigação. Em seguida, trazemos uma síntese teórica sobre o trabalho do professor sob o ponto de vista dos recentes estudos do ISD (tanto no Brasil como no exterior), com enfoque especial para a problemática dos gestos didáticos. Para ilustrar a discussão teórica, apresentamos uma análise do desenvolvimento do primeiro módulo da SD elaborada colaborativamente para a intervenção em sala de aula. Essa análise foca o trabalho docente pelo viés dos gestos didáticos (fundadores e específicos) na mobilização da ferramenta SD.

Acreditamos que pesquisas como essas, que explicitam o trabalho docente pelo viés dos gestos didáticos, que o tire da obscuridade da sala de aula, representam uma excelente ferramenta para a formação docente - tanto inicial, como continuada. Isso porque é essencial, na formação do professor, uma discussão teórico-metodológica em relação não somente aos saberes científicos e disciplinares, mas também aos saberes didáticos, experienciais, aos saberes que envolvem o agir docente em toda a sua complexidade multimodal: agir discursivo, pragmático, atitudinal, gestual, corporal etc.

\section{O contexto da pesquisa colaborativo-intervencionista}

A fonte da investigação em pauta ${ }^{2}$ é, em síntese, uma intervenção em campo, efetuada em um contexto escolar público durante o ano de 2009, que teve como colaborador (e professor regente), uma professora em início de carreira e, como locus de intervenção, um sexto ano de uma escola da periferia de Londrina/PR. Tal intervenção teve como objetivo desenvolver um trabalho de apropriação de uma prática de linguagem configurada em um gênero de texto - a carta de reclamação -, tendo como suporte teórico-metodológico o instrumental didático proposto pelo Grupo de Genebra, a fim de que ele fosse alvo de validação em contexto específico da escola pública brasileira. A validação didática, segundo $\operatorname{Dolz}(2010, \mathrm{~s} / \mathrm{p}$.):

${ }^{2}$ Este artigo é apenas um recorte da investigação maior, fruto de nossa pesquisa de doutoramento. 
pretende analisar o progresso, o aprendizado dos alunos. Depois de uma sequência didática é necessário verificar o quanto o menino progrediu na escrita. Segundo, é importante verificar a legitimidade e a coerência dos objetos de ensino do ponto de vista da transposição didática. As características do gênero escolhido são pertinentes para o ensino da leitura ou da escrita? A didatização é adequada em função do grupo de alunos? Terceiro, a validação didática examina também as possibilidades de os professores implementarem as atividades propostas nas suas condiçóes de trabalho.

O termo validação, no dicionário Houaiss, significa "ação de tornar ou declarar algo válido; legitimação, ratificação". Para que algo possa ser declarado "legítimo", é preciso investigá-lo a fundo, tomá-lo como um todo para decompô-lo em partes a serem analisadas, compreendidas no seu funcionamento. A validação didática a que esta pesquisa se propôs teve por objetivo não apenas "legitimar" o instrumental, mas também: apontar problemas, dificuldades, sugestões de mudanças ou adaptações, evidenciar a necessidade de reestruturação de conceitos, teorias, métodos e explicitar novas teorias, métodos que pudessem aflorar no percurso.

Ela teve por finalidade investigar todo o processo da implementação do projeto didático relativo à transposição didática (CHEVALLARD, 1984) da carta de reclamação, articulando três elementos essenciais desse processo: os objetos/instrumentos de ensino, os alunos (e o desenvolvimento de suas capacidades linguageiras) e o professor (no seu agir didático). É na dialética desses três eixos que se ancoram as nossas análises.

O caráter colaborativo da pesquisa advém do fato de o professorcolaborador da pesquisa ter participação ativa no desenvolvimento da investigação. Todo o processo de intervenção didática - incluindo a escolha do gênero "carta de reclamação" e a elaboração da SD - foi pensado de forma colaborativa, numa interação permanente entre professor de sala de aula/ professor em formação (o qual denominamos professor-colaborador) e pesquisador/formador (autora deste artigo). Nesse tipo de pesquisa, "o pesquisador não é um observador passivo que procura entender o outro, que também, por sua vez, não tem um papel passivo. Ambos são coparticipantes ativos no ato da construção e de transformação do conhecimento" (BORTONI-RICARDO; PEREIRA, 2006).

$\mathrm{Na}$ nossa pesquisa, optamos por uma dinâmica diferenciada em que a SD não seria feita antes da intervenção, mas durante o desenvolvimento do projeto didático, o que nos proporcionou ajustes na sua elaboração, em tempo 
quase real. Dentro da perspectiva colaborativa, todo o processo de construção das ferramentas didáticas utilizadas no projeto de sala de aula - tanto na fase da transposição didática interna como externa (DOLZ; GAGNON; CANELAS-TREVISI, 2009) - foi desenvolvido em colaboração com a professora, em uma dupla articulação de objetivos: a formação docente e o processo de ensino-aprendizagem. Ou seja, o processo de formação docente se realizava ao mesmo tempo em que desenvolvíamos as ferramentas da intervenção, colocávamos o projeto em prática em sala de aula e fazíamos as reconcepçôes (MACHADO; LOUSADA, 2010) necessárias em relação à planificação inicial da SD. Diferentemente dos cursos de capacitação docente tradicionais, em que a prática vem geralmente desarticulada da teoria, nesse modelo de formação não há como separar essas duas instâncias, uma vez que para a prática se realizar é preciso uma teoria que a sustente, sendo que essa sempre está ancorada nos resultados concretos, em um processo dialético.

\section{O trabalho docente como um agir sociointerativo}

Segundo Bronckart (2006), as ações/atividades humanas não podem ser analisadas somente por observações diretas das condutas dos sujeitos, já que elas são apreendidas, sobretudo, por um processo interpretativo mediado pela linguagem dos actantes envolvidos, ou melhor, pelos textos (orais ou escritos) que a materializam.

Esses textos que se referem a uma determinada atividade social exercem influência sobre essa atividade e sobre as ações nela envolvidas; ao mesmo tempo em que refletem representações/interpretações/avaliações sociais sobre essa atividade e sobre essas ações, podendo contribuir para a consolidação ou para a modificação dessas mesmas representações e das próprias atividades e ações (MACHADO et al., 2009).

Aceitamos, assim como Bronckart (2006), a importância fundamental da mediação da linguagem no processo interpretativo das ações humanas. Entretanto, não podemos desconsiderar o papel das observações diretas das condutas/comportamentos dos actantes na investigação do processo acional. Entendemos que o filtro da linguagem é primordial nesse processo interpretativo, mas que, em certos momentos, os comportamentos, atitudes, gestos do sujeito também precisam ser levados em consideração para a análise do seu agir. Segundo Bakhtin/Volochinov (1986, p. 124), "a comunicação verbal é sempre acompanhada por atos sociais de caráter não verbal (gestos de 
trabalho, atos simbólicos de um ritual, cerimônias, etc.), dos quais ela é muitas vezes apenas o complemento, desempenhando um papel meramente auxiliar”. Dessa forma, assim como Nascimento (2011a), consideramos que o trabalho do professor se constitui tanto por movimentos discursivos como pragmáticos.

Dessa forma, é na interpretação dos textos produzidos na/para a atividade didática, em articulação com as observações dos gestos multimodais do professor, que devemos nos debruçar quando formos analisar a atividade do trabalho docente. Atividade essa representada, na nossa pesquisa, pelo esquema tripolar da atividade de trabalho do professor (MACHADO; BRONCKART, 2009), o qual denominamos esquema de mediação formativa, como mostra a Figura 1, a seguir:

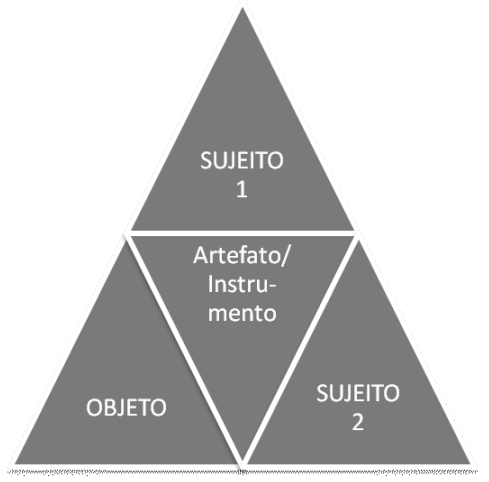

FIGURA 1 - Esquema de mediação formativa

Os vários esquemas de mediação formativa construídos durante a nossa pesquisa colaborativo-intervencionista - tanto no nível da transposição didática externa como intern $a^{3}$ - baseiam-se, assim, na interação de sujeitos (pesquisador-professor ou professor-alunos) com certo objeto, por meio da mediação de instrumento(s) didático(s).

A partir de algumas noçóes da Clínica da Atividade (CLOT, 2007), tomamos a atividade didática como uma trama que tece:

\footnotetext{
${ }^{3}$ Transposição didática interna compreende a passagem do conhecimento científico do objeto em foco ao conhecimento a ensinar. Já a transposição didática externa compreende a passagem do conhecimento a ensinar ao conhecimento ensinado e aprendido.
} 
1) prescriçôes genéricas (agir fora das restrições impostas pelo trabalho);

2) pré-figurações específicas (agir em situação de trabalho), implícitas ou explícitas, oriundas de fontes externas ou do próprio trabalhador;

3) planificaçôes de atividades, tarefas e dispositivos didáticos;

4) um agir em situação de trabalho configurado pela interação entre atores e/ ou agentes e mediado por recursos externos (ferramentas/instrumentos) e internos ao indivíduo (capacidades).

Ressaltamos também que a atividade do professor não se limita ao que é realizado por ele em situação de trabalho, mas pressupõe também o que ele não chega a realizar, o que se omite a fazer, o que desejaria ter feito etc. Ou seja, o trabalho real do professor vai muito além do trabalho realizado efetivamente, seja em sala de aula ou fora dela (CLOT, 2007).

Freqüentemente, no domínio do ensino, o não realizado é mais importante do que o que foi efetuado; o fato de que tudo corre bem não gera necessariamente uma satisfação no professor, que não pode ir até onde queria; as escolhas feitas e as decisões tomadas, mesmo que sejam julgadas eficazes por ele, não estão isentas de dúvidas e de incertezas no tocante à sua validade. $\mathrm{Na}$ atividade, [...] o realizado e o nãorealizado têm a mesma importância; mas, além disso, se inscrevem numa dinâmica em que são colocados em perspectiva: como fazer o que não foi feito?; como retomar o que não funcionou?, etc. (AMIGUES, 2004, p. 40 - grifos do autor).

$\mathrm{Na}$ atividade didática desenvolvida pela nossa pesquisa, essas reflexões sobre o não realizado, o que poderia ter sido feito de outra forma, as várias reconcepções (MACHADO; LOUSADA, 2010; LOUSADA, 2006) necessárias no curso do trabalho realizado foram, muitas vezes, colocadas em pauta na hora da planificação da SD. Um caso específico ocorrido durante o desenvolvimento das atividades foi a constatação de que havia necessidade de a professora negociar com os alunos regras de comportamento na sala de aula, pois a indisciplina estava comprometendo o desenvolvimento das atividades didáticas, e a professora acabava se sentindo desorientada sobre o que fazer e o que não fazer. Essa constatação nos levou a uma reconcepção em relação ao projeto inicial da SD. Na versão final da SD, elaboramos um módulo (módulo 2) justamente para planificarmos ações que trabalhassem as regras de sala de aula. 
É preciso pontuar também que o trabalho docente não pode ser visto sob uma perspectiva puramente mecânica, uma vez que o objeto da atividade do professor não pertence ao mundo físico, mas ao mundo cognitivo (MACHADO; BRONCKART, 2009):

Sendo a atividade educacional constitutivamente interativa, é preciso considerar que nela emerge uma dimensão de liberdade, pois o professor não pode agir diretamente sobre os processos mentais do aluno. Ele apenas vai criar espaços, ambientes que permitam que as transformaçōes desejadas possam ocorrer, o que nunca está garantido, dado que o aluno é o real agente de seu desenvolvimento e que sua liberdade pode leválo a recusar-se a entrar nos ambientes criados pelo professor, resistir a eles, ir em outra direção etc. (MACHADO, 2009, p. 79).

É justamente por isso que na concepção interacionista do ensinoaprendizagem, o professor é visto como um mediador do processo, assim como todos os instrumentos por ele mobilizados, para criar justamente esses "espaços" de transformações.

\section{Trabalho Prescrito, Planificado e Realizado}

Consideramos, assim como o faz Machado (2009), a existência de três níveis de trabalho: o trabalho prescrito, o qual engloba "um conjunto de normas e regras, textos, programas e procedimentos que regulam as ações" do trabalhador (p. 80); o trabalho planificado, constituído de um conjunto de textos pré-figurativos que "explicitam o conjunto das tarefas, seus objetivos, suas condiçôes materiais e sua forma de desenvolvimento das açōes projetadas pelo próprio trabalhador" (p. 81); e o trabalho realizado, "o conjunto de açôes efetivamente realizadas" (p. 80).

Quanto ao primeiro nível, do trabalho prescrito, Machado (2009, p. 8081) pontua que, de fato, "em qualquer atividade de trabalho institucional ou empresarial, o trabalhador encontra-se diante de restriçóes provenientes das instituições/empresas, que dão uma configuração inicial à sua ação, frequentemente explicitadas em textos instrucionais ou procedimentais". No caso do trabalho docente, esses textos emergem de três instâncias principais, hierarquicamente representadas pelos textos oficiais da educação de nível federal (os Parâmetros Curriculares Nacionais - PCN), estadual (as Diretrizes Curriculares Estaduais - DCE), e local (os Projetos Político-Pedagógicos PPP). Esses documentos (e outros que prescrevem o agir do professor) 
parametrizam a ação docente, uma vez que trabalham com a padronização da atividade de ensino, prescrevendo concepções de ensino-aprendizagem que devem subsidiar a prática docente, objetivos, conteúdos e objetos de ensino, procedimentos didáticos, formas de agir do professor etc. "Essas prescriçôes, de modo teórico, não podem ser vistas como negativas, mas como artefatos disponibilizados para o professor e que podem facilitar o seu trabalho." (MACHADO; LOUSADA, 2010, p. 627). Elas, embora não limitando completamente o trabalho do professor, configuram-se em "vozes" poderosas que exercem forte coerção nas suas ações, ou, pelo menos, na sua forma de discursar sobre o ensino (muitos professores acabam incorporando apenas o "discurso" desses documentos, mas não os colocando em prática). Essas "vozes" são também, em vários momentos, "relembradas", "reafirmadas" em encontros pedagógicos, cursos de formação continuada, de pós-graduaçãa etc.; o que acaba reforçando o seu valor prescritivo.

Outro texto que pode ser enquadrado nas prescriçóes educacionais é, no caso do contexto brasileiro da escola pública, o próprio livro didático adotado pelo professor:

Didático [...] é o livro que vai ser utilizado em aulas e cursos, que provavelmente foi escrito, editado, vendido e comprado, tendo em vista essa utilização escolar e sistemática. Sua importância aumenta ainda mais em países como o Brasil, onde uma precaríssima situação educacional faz com que ele acabe determinando conteúdos e condicionando estratégias de ensino, marcando, pois, de forma decisiva, o que se ensina e como se ensina o que se ensina (LAJOLO, 1996, p. 4).

É comum, pois, o livro didático prescrever o trabalho do professor, orientando seu agir, pré-selecionando os conteúdos a serem ensinados, a metodologia de ensino, as concepções teóricas que subsidiam a prática etc.

O trabalho prescrito também pode estar no nível do implícito, consubstanciado nas regras não expressas linguisticamente pelos gêneros $d a$ atividade profissional (CLOT, 2007) que regem os comportamentos dos sujeitos em situação de trabalho.

Esse referencial elaborado em comum estabelece regras não escritas e não imutáveis numa situação comunicacional que pressupõe a elaboração comum. Ele inscreve as habilidades consideradas na história de um coletivo. [...] A regra não escrita estrutura as diversas espécies de trocas nas quais os operadores [trabalhadores em geral] estão engajados (CLOT, 2007, p. 37). 
No caso do trabalho do professor, o gênero da atividade "aula" pressupõe vários outros gêneros da atividade docente que não estão sistematizados nos documentos escritos, mas que regem o agir docente. Esses modelos do agir vão sendo modificados no decorrer da história, a partir das coerçôes sociais, sem que, muitas vezes, o professor tome consciência dessas mudanças. E, ao não se conscientizar dessas alteraçôes, ele acaba não se preparando profissionalmente para enfrentá-las. O sistema também, muitas vezes, se omite em dar formação profissional para o professor agir nesse novo contexto. Também ocorre de o professor receber formação para uma nova realidade educacional, mas resistir em aceitá-la ou mudar sua prática, consolidada em anos de experiência na sala de aula. É o que ocorre atualmente, por exemplo, com o evento da "democratização escolar", em que professores precisam adaptar a sua prática para trabalhar com a heterogeneidade linguística (ligada a fatores sociais/econômicos/culturais) dos alunos.

Quanto ao trabalho planificado, esse se consubstancia nos textos de planejamento do agir docente, elaborados pelo próprio professor. Seria o trabalho prescrito, mas de ordem interna - uma autoprescrição. Sabemos que no contexto brasileiro, na atualidade, essa etapa do agir docente não é priorizada. Nos cursos de formação inicial, é comum se ressaltar a importância de o professor planejar as suas açôes didáticas. Nesses cursos, aprende-se a elaborar planos de ensino, planos de aula. Entretanto, na realidade do dia a dia do professor, sabemos que o excesso de atribuição de carga horária em sala de aula, as mínimas horas-atividade que os docentes têm para preparar suas aulas, corrigir trabalhos e provas, os longos deslocamentos de uma escola a outra a que muitos deles têm de se submeter para cumprir sua carga horária semanal (entre outros fatores) não contribuem para que o professor faça a planificação de seu trabalho. Assim, é comum o docente tomar unicamente o livro didático como texto pré-figurativo da sua ação. Nos cursos de formação que ministramos, é comum ouvirmos depoimentos de professores que até planificam as suas açôes, mas sem fazer o devido registro, sem tornar explícito esse momento pré-intervenção didática. Fato que compromete, inclusive, a própria progressão curricular, uma vez que a escola não fica com arquivos do trabalho do professor, dificultando, muitas vezes, a continuidade do trabalho didático. Outros professores relatam que, ao tentar planificar sua ação, acabam fazendo "recortes" de outros manuais didáticos, que não seja o usado em sala de aula. Ou seja, o livro didático acaba novamente direcionando o trabalho planificado, mesmo que de forma indireta. 
No último nível, temos, como vimos, o trabalho realizado pelo professor. Segundo Machado (2009), é apoiando-se nas prescrições do trabalho $\mathrm{e}$, às vezes, no planejamento do agir, que o "trabalhador desenvolve o chamado trabalho realizado, isto é, o conjunto de condutas (verbais ou não verbais) efetivamente observáveis na situação, que sempre vai apresentar algum distanciamento em relação ao que foi prescrito (p. 81). Esse distanciamento entre o prescrito e o realizado é uma condição natural, inevitável em qualquer atividade de trabalho.

A distância entre trabalho prescrito e realizado é natural: ela provém da necessidade de adaptação das prescrições, de certa maneira “impessoais" (ROGER, 2007), já que elaboradas para um coletivo de trabalhadores, à situação particular de trabalho de cada professor/ trabalhador, como se vê comumente nas instituições escolares (AMIGUES, 2002). As adaptações que os trabalhadores fazem das prescrições, adaptando-as a seu contexto, teriam o objetivo de aumentar sua eficácia no trabalho (LOUSADA, 2011, p. 42).

É nesse ponto que entra outro conceito trabalhado pelas ciências do trabalho: a reconcepção (MACHADO; LOUSADA, 2010; LOUSADA, 2006). O professor sempre faz um recorte pessoal das prescrições externas para atuar no seu contexto de ensino, ou seja, as redefine, dá uma nova concepção a essas prescrições. Isso acontece também com a própria planificação interna do seu trabalho, que, na sua realização efetiva, também precisa ser adaptada para dar conta das ocorrências não previstas inicialmente. A reconcepção é, pois, esse processo natural de redefinição do prescrito. Segundo Saujat (2002), é justamente essa reconcepção que garante a saúde, a identidade e a competência do professor. Isso não significa que toda reconcepção seja positiva, no sentido de ser a melhor alternativa para o desenvolvimento da atividade de ensinoaprendizagem. O que estamos pontuando é que ela faz parte do processo natural do trabalho do professor, é inevitável. É claro que nessa reconcepção estão envolvidos vários fatores, como: o contexto específico da ação, os saberes e as capacidades do agir do professor, as concepçōes de ensino e de língua (no caso da disciplina de língua portuguesa) que norteiam, mesmo que inconscientemente, o trabalho do professor, as condições específicas do locus de trabalho docente etc. Ou seja, para analisar uma reconcepção é preciso levar em consideração uma rede de fatores que estão em jogo no trabalho docente. Segundo Lousada (2011), a reconcep̧̧ão das prescriçôes iniciais pode ser vista também como uma maneira de se apropriar de ferramentas disponíveis no 
coletivo de trabalho, transformando-as em instrumentos para a ação (gênese instrumental-Rabardel, 1995).

Ainda sob o ponto de vista do trabalho planificado, é importante destacar que a planificação do agir, feita pelo próprio professor, também é uma forma de trabalho realizado. Segundo Machado e Lousada (2010), não podemos sucumbir ao discurso dominante de que o trabalho do professor é somente o de "dar aulas". No caso da nossa pesquisa, as planificações das atividades didáticas desempenham dupla função em relação ao trabalho docente: de um lado, já faz parte do trabalho realizado do professor, de outro, pertence à categoria do trabalho planificado, uma vez que define conteúdos e delimita tarefas para o professor e para os alunos. Mesmo considerando a planificação da ação didática uma etapa do trabalho realizado do professor, entendemos que o grande locus observável desse nível de trabalho é a sala de aula. É lá que se concretiza efetivamente o agir em situação de trabalho, são presentificadas as ações didáticas, se constroem os objetos de ensino verdadeiramente, onde os saberes a ensinar transformam-se em saberes efetivamente ensinados e aprendidos, sob a maestria de um profissional da educação - o professor.

De acordo com Bulea (2010), atualmente percebe-se um crescente interesse nas análises do trabalho realizado do professor, ou no que a autora chama de análises das práticas, em um processo que articula formação, instrumentos e objetos do agir profissional e a sua efetivação concreta. Isso se explica pelo fato de o mundo do trabalho estar em constante transformação, necessitando, assim, uma investigação ininterrupta de todo o complexo que movimenta as práticas profissionais.

[...] as mudanças permanentes no campo do trabalho (complexidade das tarefas, evolução rápida dos entornos e das ferramentas etc.) ora geram, ora readquirem novos dispositivos para assegurar permanentemente a articulação entre os conteúdos de formação e as situações profissionais, melhor dizendo, de pré-orientar a constituição de alguns desses conteúdos para sua elaboração em situações de trabalho efetivas (BULEA, 2010, p. 29).

Nesse sentido, investigar o trabalho realizado do professor, a partir de uma visão ampla que engloba tanto o processo formativo como os objetos e instrumentos que orientam as práticas realizadas em situação efetiva de trabalho, é ajudar na profissionalização do trabalho docente e na consolidação da ideia do ensino como trabalho (SOUZA-e-SILVA, 2004). 


\section{Gestos Didáticos}

Neste tópico vamos nos deter no agir do professor como um instrumento mediador da atividade de ensino-aprendizagem. Para tratar desse instrumental didático, nos apoiamos na noção de gestos profissionais, ou gestos didáticos $^{4}$ no caso específico do trabalho do professor (AEBY-DAGHÉ; DOLZ, 2008; NASCIMENTO, 2011a, 2011b). Os gestos didáticos são movimentos discursivos e pragmáticos (NASCIMENTO, 2011a) - ou seja, verbais e não verbais -, observáveis no trabalho do professor que visam sempre à aprendizagem do aluno.

Portadores de significados, esses gestos são integrantes do complexo sistema social da atividade de ensino regida por regras e códigos convencionais, estabilizados por práticas seculares constitutivas da cultura escolar. ${ }^{5}$ (AEBY-DAGHÉ; DOLZ, 2008, p. 83).

Nesse sentido, podemos falar em duas categorias de gestos didáticos (AEBY-DAGHÉ; DOLZ, 2008; NASCIMENTO, 2011a, 2011b): a) os gestos fundadores, relacionados às práticas estabilizadas convencionalmente pela instituição escolar; e b) os gestos específicos, relacionados às necessidades singulares impostas pela transposição didática interna de um objeto de ensino.

Sendo assim, na perspectiva adotada pela nossa pesquisa, os gestos didáticos especificos estão sempre a serviço da construção dos objetos de ensino, no processo da transposiçãa didática interna. Ou seja, eles moldam-se às necessidades da didatização dos objetos escolares, assim como esses objetos vão sendo internalizados à medida que os gestos didáticos do professor vão se incorporando à atividade de ensino-aprendizagem.

Acreditamos, dessa forma, assim como Aeby-Daghé e Dolz (2008), que a dinâmica das transformaçôes dos objetos a ensinar é controlada pelos gestos didáticos específicos: "é pelos gestos didáticos que o professor delimita o objeto,

\footnotetext{
${ }^{4}$ Neste trabalho, consideramos os gestos didáticos do professor como um subconjunto dos gestos profissionais, uma vez que consideramos a atividade do professor dentro do âmbito profissional - como trabalho.

${ }^{5}$ Texto original, em francês: «Porteurs de significations, ces gestes s'integrent dans le systeme social complexe de l'activité enseignante qui est rege par des regles et des codes conventionnels, stabilises par des pratiques séculares constitutives de la culture scolare».
} 
que ele o mostra, que ele o decompõe, que ele o ajusta às necessidades dos alunos, isto é, que ele o transforma em vista da aprendizagem ${ }^{6}$ " (p. 84).

Quanto aos gestos didáticos fundadores, Aeby-Daghé e Dolz (2008, p. 85-86), com base em suas pesquisas no contexto suíço, propóem a seguinte modelização:

\section{QUADRO 1}

Gestos didáticos fundadores

\begin{tabular}{|l|l|}
\hline $\begin{array}{l}\text { Gestos Didáticos } \\
\text { Fundadores }\end{array}$ & \multicolumn{1}{|c|}{ Descrição } \\
\hline Presentificação & $\begin{array}{l}\text { Tem por finalidade apresentar aos alunos um objeto social de referência, no } \\
\text { suporte adequado, que passará por um processo de didatização. }\end{array}$ \\
\hline Delimitação & $\begin{array}{l}\text { Focaliza uma (ou mais) dimensão ensinável do objeto de ensino- } \\
\text { aprendizagem - desconstrução e colocação em evidência dessa dimensão. }\end{array}$ \\
\hline $\begin{array}{l}\text { Formulação de } \\
\text { tarefas }\end{array}$ & $\begin{array}{l}\text { Porta de entrada para os dispositivos didáticos; seu estudo envolve a } \\
\text { utilização de comandos. }\end{array}$ \\
\hline $\begin{array}{l}\text { Criação de dispo- } \\
\text { sitivos didáticos }\end{array}$ & $\begin{array}{l}\text { Os meios para enquadrar uma atividade escolar - pressupõe a mobilização } \\
\text { de suportes (textos, esquemas, objetos reais etc.). }\end{array}$ \\
\hline $\begin{array}{l}\text { Utilização da } \\
\text { memória }\end{array}$ & $\begin{array}{l}\text { Implica colocar na temporalidade o objeto de ensino e convocar as } \\
\text { memórias das aprendizagens, para permitir utilizá-las mais tarde. }\end{array}$ \\
\hline Regulação & $\begin{array}{l}\text { Inclui dois fenômenos intrinsecamente relacionados: as regulaçôes internas } \\
\text { e as regulaçóes locais. As regulaçóes internas, centradas nas estratégias para } \\
\text { obter as informaços sobre o estado dos conhecimentos dos alunos } \\
\text { (processo diagnóstico), podem estar no início, durante ou no fim de } \\
\text { uma atividade didática (na SD, a avaliação da primeira produção do aluno } \\
\text { é um ato de regulação didática interna). As regulações locais operam } \\
\text { durante as atividades didáticas, em uma discussão com os alunos ou } \\
\text { no decorrer de uma tarefa. A avaliação é considerada um gesto } \\
\text { didático específico de regulação. }\end{array}$ \\
\hline Institucionalização & $\begin{array}{l}\text { "Constituída pelos gestos direcionados para a fixação do saber (externo) } \\
\text { que deve ser utilizado pelos aprendizes nas circunstâncias novas (internas) } \\
\text { em que serão exigidos" (NASCIMENTO, 201 la, p. 427). Ela se apresenta } \\
\text { sob a forma de uma generalização envolvendo a apresentação de } \\
\text { informações sobre o objeto de ensino e especialmente colocando em } \\
\text { evidência os novos aspectos desse objeto que os alunos devem aprender. }\end{array}$ \\
\hline
\end{tabular}

${ }^{6}$ Texto original em francês: "Dans Ce cadre, c'est par les gestes didactiques que l'enseignant délimite l'objet, qu'il le montre, qu'il le décompose, qu'il l'ajuste aux besoins des élèves, c'est-à-dire qu'il le transforme en vue de l'apprentissage.»

7 Termo usado em francês: "présentification".

${ }^{8}$ Termos usados em francês: "pointage/élémentarisation". 
Segundo Nascimento (2011a, p. 434), os gestos didáticos fundadores

presentificam e topicalizam um conteúdo em sala de aula, fazendo emergir um sistema de gestos didáticos no interior do sistema didático, tais como: 1) a forma como o professor inicia a topicalização de um objeto novo; 2) a maneira como formula e regula as tarefas em sala de aula; 3) a mediação por instrumentos para regular as atividades em sala; 4) a maneira como institucionaliza o conteúdo.

Sob esse ponto de vista, para as análises do nosso contexto de investigação, tomamos por base os gestos didáticos fundadores elencados pelos autores genebrinos, procurando observar as particularidades do nosso contexto, além de analisar os gestos específicos do professor no processo de transposição didática interna do objeto unificador do ensino da SD.

Acreditamos que o desenvolvimento da capacidade de agir do professor se processa em uma zona de desenvolvimento potencial ${ }^{9}$ (NASCIMENTO, 2011a) em uma dialética constante entre os saberes científicos, disciplinares e didáticos da sua área. Saberes esses acumulados no processo das formações inicial e continuada, fornecidos pelo coletivo de trabalho (na forma de memória coletiva ou de textos institucionais, de cunho prescritivo) e internalizados durante a sua atividade profissional, nas execuçōes de tarefas exigidas pelos mecanismos da transposição didática externa e interna dos objetos de ensino.

Com base em Vigotsky, Nascimento (2011b) se refere ao movimento de "apropriação dos gestos alheios tomados de empréstimo de pessoas em quem se deposita confiança”. Para a autora, no interior de uma zona de desenvolvimento potencial de uma atividade, a imitação de um gesto de outrem pode ser fonte externa da própria atividade, constituindo então em recurso interno do próprio desenvolvimento.

\footnotetext{
${ }^{9}$ A Zona de Desenvolvimento Potencial (ZPD) é definida como a distância entre o nível de desenvolvimento atual da criança - detectado pela capacidade de resolver determinado problema individualmente - e o nível de desenvolvimento potencial determinado pela capacidade de resolução de certo problema com o auxílio de pessoas mais experientes (VIGOTSKI, 2008). Assim, é a partir da postulação da existência de dois níveis de desenvolvimento - um real (NDR - a/b) e um potencial (NDP) - que Vigotski define a ZPD.
} 


\section{SD da carta de reclamação: esquemas de mediação formativa}

Nesta seção analítica centramos nosso olhar na transposiçāo didática interna, a qual envolve a transformação dos saberes a ensinar em saberes ensinados e aprendidos, assim como "a criação de dinâmicas e a sua transformação em situações de ensino" (DOLZ; GAGNON; CANELASTREVISI, 2009, p. 74 - tradução nossa $^{10}$ ).

Mesmo que o artigo não aborde a totalidade da SD desenvolvida na pesquisa maior, uma vez que nos propomos a analisar apenas o seu primeiro módulo, trazemos, a seguir, um quadro cujo objetivo é demonstrar os esquemas de mediação formativa que foram acionados durante o desenvolvimento geral da SD e proporcionar, assim, uma visão global da atividade de ensino desenvolvida durante a transposição didática interna da carta de reclamação:

\section{QUADRO 2}

Esquemas de mediação formativa da transposição didática interna da carta de reclamação

\begin{tabular}{|l|l|l|l|l|}
\hline \multicolumn{5}{|c|}{ TRANSPOSIÇÃO DIDÁTICA INTERNA: } \\
dos saberes a ensinar aos saberes ensinados e aprendidos \\
\hline $\begin{array}{l}\text { Esquema de } \\
\text { Mediação } \\
\text { Formativa }\end{array}$ & Sujeito 1 & Sujeito 2 & $\begin{array}{l}\text { Objetos da } \\
\text { Interação }\end{array}$ & Instrumentos da interação \\
\hline $\begin{array}{l}\text { 1) Produção da } \\
\text { carta de reclamação } \\
\text { (esquema central) }\end{array}$ & Professor & Alunos & $\begin{array}{l}\text { Gênero “carta } \\
\text { de reclamação" }\end{array}$ & SD da carta de reclamação \\
\hline $\begin{array}{l}\text { 1A) Módulo 01 } \\
\text { Professor }\end{array}$ & Alunos & $\begin{array}{l}\text { Motivação para a } \\
\text { escrita da carta } \\
\text { de reclamação }\end{array}$ & Atividade do púlpito \\
\hline 1B)Módulo 03 & Professor & Alunos & $\begin{array}{l}\text { Primeira produção } \\
\text {-avaliação } \\
\text { diagnóstica }\end{array}$ & $\begin{array}{l}\text { Primeira produção } \\
\text { da carta de reclamação }\end{array}$ \\
\hline 1C) Módulo 05 & Professor & Alunos & $\begin{array}{l}\text { Modalidades } \\
\text { diferentes de cartas }\end{array}$ & $\begin{array}{l}\text { Dispositivo didático } \\
\text { "Leitura e identificação de } \\
\text { tipos diferentes de cartas” }\end{array}$ \\
\hline
\end{tabular}

${ }^{10}$ Texto original em francês: «La transposition interne concerne non seulement le passage des savoirs disciplinaires à enseigner aux objets enseignés, mais la dynamique même de création et de transformation de ces derniers dans les situations didactiques». 


\begin{tabular}{|c|c|c|c|c|c|}
\hline 1D) & $\begin{array}{l}\text { Módulo } 06 \\
\text { Módulo } 07\end{array}$ & Professor & Alunos & $\begin{array}{l}\text { Plano textual } \\
\text { global da carta } \\
\text { de reclamação; } \\
\text { relato e descrição }\end{array}$ & $\begin{array}{l}\text { Dispositivos didáticos: } \\
\text { "Estrutura da carta de } \\
\text { reclamação"; "Estrutura } \\
\text { geral da carta de reclama- } \\
\text { ção"; tarefa simplificada de } \\
\text { escrita com relatos e } \\
\text { descrições }\end{array}$ \\
\hline 1E) & Módulo 09 & Professor & Alunos & $\begin{array}{l}\text { Planificação textual } \\
\text { da sequência } \\
\text { argumentativa }\end{array}$ & $\begin{array}{l}\text { Debates orais sobre fatos } \\
\text { polêmicos; atividade de } \\
\text { observação e análise de } \\
\text { textos; dispositivos } \\
\text { didáticos: "Argumentação" } \\
\text { e "Opinião e Argumentos" }\end{array}$ \\
\hline 1F) & $\begin{array}{l}\text { Módulo } 02 \\
\text { Módulo } 10\end{array}$ & Professor & Alunos & $\begin{array}{l}\text { Conteúdo temático } \\
\text { das reclamações }\end{array}$ & $\begin{array}{l}\text { Entrevista com pessoas da } \\
\text { comunidade; discussão } \\
\text { oral; textos sobre os } \\
\text { temas das cartas }\end{array}$ \\
\hline 1G) & Módulo 11 & Professor & Alunos & $\begin{array}{l}\text { Elementos articu- } \\
\text { ladores do texto }\end{array}$ & $\begin{array}{l}\text { Dispositivos didáticos: } \\
\text { "Quebra-cabeça de } \\
\text { frases com elementos } \\
\text { articuladores" e "Elementos } \\
\text { articuladores: construção } \\
\text { de frases" }\end{array}$ \\
\hline $1 \mathrm{H})$ & $\begin{array}{l}\text { Módulo } 08 \\
\text { Módulo } 12 \\
\text { Módulo } 13\end{array}$ & Professor & Alunos & $\begin{array}{l}\text { Produções textuais } \\
\text { - avaliação formativa }\end{array}$ & $\begin{array}{l}\text { Dispositivo didático } \\
\text { "Ficha de revisão: carta } \\
\text { de reclamação"; atividades } \\
\text { de escrita e reescrita textual }\end{array}$ \\
\hline
\end{tabular}

Como vemos, essa etapa da investigação é orientada por um esquema de mediação formativa central, que tem como objeto a escrita da carta de reclamação e, como instrumento mediador, a SD elaborada para a apropriação desse gênero. Os sub-esquemas (1A-1G) referem-se aos objetos de ensino decompostos da carta de reclamação.

Nas análises dos esquemas de mediação formativa da SD, tomamos como eixo central os gestos fundadores: desenvolvimento das atividades e tarefas; utilização dos dispositivos didáticos; mobilização da memória das aprendizagens; acionamento da regulação e da institucionalização (AEBYDAGHÉ; DOLZ, 2008). É na mobilização desses gestos fundadores que emergem os gestos didáticos específicos do professor, os quais são alvos de sistematização por parte da nossa pesquisa.

Nesse artigo, como já mencionado, apresentamos somente a análise do primeiro esquema de mediação formativa, concretizado no módulo 1 da SD, 
cujo objeto foi a motivação para a escrita da carta de reclamação. Como instrumento de análises, utilizamos gravações das aulas em áudio-visual, anotações feitas no diário da pesquisadora, bem como atividades e produções dos alunos, compiladas durante o desenvolvimento da SD.

\section{Módulo 1 da SD: a motivação para a atividade de escrita da carta de reclamação}

Um dos diferenciais da metodologia de ensino da língua proposta pelo ISD é justamente a primeira fase da SD: a apresentação de um problema de comunicação aos alunos.

A primeira dimensão é a do projeto coletivo de produção de um gênero oral ou escrito, proposto aos alunos de maneira bastante explícita para que eles compreendam o melhor possível a situação de comunicação na qual devem agir; qual é, finalmente, o problema de comunicação que devem resolver, produzindo um texto oral ou escrito (DOLZ; NOVERRAZ; SCHNEUWLY, 2004, p. 99 - grifos dos autores).

Essa etapa é responsável por proporcionar a motivação para a escrita de um gênero. Ou seja, a atividade de escrita não deve ser motivada simplesmente por uma necessidade didática de aprendizado. Como motivação para a escrita da carta de reclamação, a nossa SD propôs a "Atividade do púlpito". Ela consistia em usar um recurso didático existente em sala de aula, a $T V$ pendrive,$^{11}$ para exibir episódios do quadro "Púlpito" do programa televisivo Altas Horas, o qual mostra integrantes da plateia protestando contra algo que os incomoda. Posteriormente, a SD propunha reproduzir o quadro "Púlpito" com os alunos para que eles também pudessem fazer os seus protestos.

Primeiramente, a nossa intenção foi colocar em evidência a "ação de reclamar", de uma maneira lúdica e sem muito vínculo com a rotina de sala de aula, para, em seguida, levar os alunos a refletir sobre as diversas formas discursivas da reclamação. O gênero "carta de reclamação" surgiria, assim, naturalmente das reflexões dos alunos. O papel do professor, como mediador dessa atividade, seria o de levar os alunos a perceber a importância de se saber reclamar com os instrumentos corretos para se conseguir a solução de um

${ }^{11}$ A TV pendrive faz parte do Projeto Multimídia, o qual destinou a todas as salas de aula da rede estadual do Paraná televisores com entradas para VHS, DVD, cartão de memória e pendrive e saídas para caixas de som e projetor multimídia. 
problema, assim como fazer com que eles tomassem consciência da significação social da escrita de uma carta de reclamação: alguém que assume o papel discursivo de cidadão para reclamar e solicitar uma solução para um problema social (no nosso caso, um problema da comunidade dos alunos). Ele também teria a tarefa de "provocar" conflitos nos alunos em relação à situação social da comunidade - pois seria dessa esfera social que emergiriam os problemas-alvo das cartas de reclamação.

Por outro lado, a ideia era desenvolver capacidades docentes para a mobilização do gênero da atividade "uso da TV pendrive", ${ }^{12}$ promovendo um processo de inclusão digital, no âmbito do agir da professora. Isso porque era a primeira vez que ela usava aquele recurso didático. Efetivamente, para realizar a atividade a docente teve de acionar a coordenação pedagógica para aprender a utilizar o equipamento, assim como usar a internet para baixar os arquivos dos episódios televisivos em seu pendrive. São ações que, a priori, parecem insignificantes, mas que tiveram resultados significativos para a formação continuada da professora. Por ela ser iniciante no exercício da profissão, e novata naquela escola, parece que tinha receio em realizar ações didáticas que não dominava totalmente, talvez para não mostrar "fragilidade" ao coletivo de trabalho. A nossa intervenção foi, dessa forma, um pretexto para que ela começasse a utilizar aquele recurso didático. Ao realizar a atividade, percebemos que houve um crescimento da sua autoestima profissional, pois, ao agir didaticamente, a professora imprimiu uma imagem de alguém que dominava o uso daquela tecnologia - por sinal, pouco usada como material didático pelos demais docentes. Isso ficou evidente na reação dos alunos durante o desenvolvimento da atividade: cochichos entre os colegas, euforia, comentários como "hoje tem TV laranja” (forma como alguns denominam o equipamento).

\subsection{Realização das atividades e tarefas}

O tipo de atividade planificada para esse módulo foi classificado por nós como "motivacional - para a escrita textual" e, o tipo de tarefa, como "participação oral". As atividades motivacionais para a escrita geralmente são trabalhadas de forma lúdica, sem uma sistematização muito rigorosa, uma vez que o objetivo é conseguir a adesão do aluno em relação a um projeto de escrita

\footnotetext{
${ }^{12}$ No contexto da escola pública paranaense, o uso da TV pendrive pode ser considerado um gênero da atividade docente, ou seja, é uma atividade tipificamente estruturada, inserida no gênero didático "aula".
} 
de um texto "real", mesmo que em um ambiente de ensino-aprendizagem. A atividade do púlpito, por essa razão, mobilizou, fundamentalmente, tarefas na modalidade oral. Essa escolha, de certa forma, foi bastante "arriscada", se levarmos em consideração o perfil da nossa intervenção: primeiro contato dos alunos com o projeto, presença de uma pessoa "estranha" na sala de aula (pesquisadora), aulas filmadas, professora com pouco domínio de sala de sala, alunos pré-adolescentes, indisciplinados, classe numerosa. Ou seja, sabíamos que seria uma aula em que a professora teria muitas dificuldades para desenvolver seu trabalho. Mas, nesse caso, os objetivos dessa etapa da SD, representados pelo gesto fundador da presentificação do projeto da escrita, tiveram peso maior na planificação das atividades e tarefas. Os alunos foram, assim, levados a perceber a importância do ato de reclamar e a tomar consciência das suas diferentes formas discursivas, sobretudo, no que diz respeito à carta de reclamação.

Como esperado, a turma recebeu a atividade com muita euforia, dificultando ainda mais o agir da professora em relação ao controle de sala de aula. Assim que terminava cada reprodução do quadro "Púlpito" do Altas Horas, os alunos gritavam, vaiavam, batiam na mesa, assim como acontece, na realidade, no programa de TV. Ou seja, para os alunos dessa faixa etária é difícil separar contextos sociais autênticos de contextos didatizados. Mas, como dissemos, isso já era esperado. Nesse caso, estávamos contando com a mediação da professora para amenizar a bagunça, uma vez que isso seria inevitável. Um gesto didático controlador da indisciplina adotado pela professora, em processo de imitação do coletivo de trabalho daquela escola, era anotar os nomes dos "bagunceiros" em um canto da lousa. Esse procedimento servia para uma posterior punição - encaminhamento do aluno à coordenação, avaliação bimestral quanto à disciplina, reclamação aos pais, etc Entretanto, esse procedimento, na maioria das vezes, não resultava em nenhuma ação efetiva, o que acabava se transformando em um gesto performático da professora, sem resultados concretos. Outro gesto controlador da indisciplina, mobilizado para esse módulo, foi tentar organizar as falas dos alunos, pedindo que eles levantassem a mão para falar. Esse gesto é muito utilizado por professores, em geral, ao trabalhar a discussão oral. Porém, quando o professor não consegue esquematizá-lo, ele acaba gerando ainda mais confusão. Isso ocorre pois é comum vários alunos levantarem a mão ao mesmo tempo, e o professor escolher um aluno, aleatoriamente, gerando reclamaçōes e inflamando ainda mais o tumulto. 
$\mathrm{Na}$ etapa da atividade do "púlpito de sala de aula", a bagunça se generalizou, pois, naquele momento, os protestos envolveram, em geral, problemas escolares como, por exemplo, reclamaçôes em relação ao professor de matemática. A professora, que não esperava esse direcionamento da atividade, uma vez que, nos nossos encontros de formação, ingenuamente, não tínhamos cogitado essa possibilidade, mobilizou um gesto didático de desvio de foco das atenções dos alunos. Após dois protestos contra o professor de matemática, e outros sobre a rotina escolar, ela intervém e fala: "Não só em relação à escola, tem outros lugares que vocês podem protestar: observem os problemas da COMUNIDADE". Ou seja, sem, explicitamente, contestar as reclamaçôes dos alunos, a professora desvia a atenção deles para outro foco, aquele privilegiado pela pesquisa.

Essa atividade, embora gerando bastante tumulto, o que impossibilitou ao professor aprofundar algumas questōes, conseguiu atingir resultados expressivos. Ela conseguiu proporcionar uma tomada de consciência em relação à ação de reclamar, verificada na participação dos alunos nas atividades; um esclarecimento em relação aos contextos discursivos das reclamações surgidas na atividade do púlpito. Esse esclarecimento ficou evidente pela participação dos alunos na sistematização contextual feita, na lousa, pela professora - tarefa do professor previamente planificada pela $\mathrm{SD}$. Os alunos perceberam que cada reclamação tem um destinatário específico e uma (ou mais) forma discursiva para se concretizar. Embora na planificação da SD tenhamos utilizado o termo "gênero textual", na transposição didática interna a professora fez uma reconcepção ao utilizar "forma de comunicação". Esse gesto didático de didatização de conceitos teóricos/técnicos é imprescindível no desenvolvimento de qualquer SD. É importante que os alunos entendam o conceito, independentemente da sua nomenclatura acadêmica. Outro ponto que mostra a importância desse módulo são as reaçōes perplexas dos alunos quando a professora diz que as cartas seriam endereçadas e enviadas aos seus destinatários reais. Comentários como "Professora, você tem certeza que o prefeito vai receber a minha carta?" (no caso da reclamação das ruas esburacadas) eclodiram na sala, mostrando que os alunos já começavam a perceber a diferença entre as "redaçôes" que normalmente faziam em sala de aula e a produção da carta de reclamação, cujo destinatário real era uma pessoa do mundo extraescolar.

Nesse módulo ainda foi solicitado uma tarefa para casa: entrevistas com pessoas da comunidade sobre os problemas locais. Essas entrevistas deveriam ser feitas a partir de duas perguntas que a professora passou na lousa. Porém, como começava a se delinear, esses alunos não tinham o hábito de fazer os 
deveres de casa. Mesmo a professora dizendo que as atividades extraclasses seriam pontuadas na nota bimestral, poucos se interessaram em realizá-las. Essa parece ser uma realidade da escola pública brasileira: há pouco comprometimento dos alunos com as atividades extraclasses, mesmo quando elas valem nota, pois a chance de eles ficarem retidos no ano é muito pequena. Normalmente, apenas são reprovados os alunos muito problemáticos. ${ }^{13}$

\subsection{Mobilização da memória, regulação e institucionalização}

Para efeito de sumarização do aprendizado dos módulos, e posterior ativação da memória didática, a planificação da SD sistematizou a escrita de um "relatório da aprendizagem" (o que os pesquisadores de Genebra chamam de "ficha de controle/constatações") a cada encerramento de módulo. Esse procedimento pode ser considerado, ao mesmo tempo, um gesto didático de regulação, ativação da memória didática e institucionalização dos objetos de ensino (gestos fundadores propostos por AEBY-DAGHÉ; DOLZ, 2008). Regulação, pois possibilita ao professor avaliar, localmente, a apreensão dos objetos didáticos trabalhados. Ativação da memória, já que opera com o resgate das aprendizagens consolidadas e como instrumento que possibilita a ativação da memória didática em momentos posteriores da SD, por ser um "registro" escrito dessas aprendizagens. Institucionalização dos objetos de ensino, uma vez que, ao resgatar as apreensões anteriores, o professor está também ativando um processo de "fixação" dos saberes subjacentes a esses objetos - saberes sociais (externos) e didatizados (internos).

Como era o primeiro dia desse procedimento, a estratégia foi apenas auxiliar a escrita dos relatórios, mas não conduzir a atividade formalmente, pois queríamos saber qual a representação inicial dos alunos em relação ao projeto de escrita da carta de reclamação e à ação de reclamar - foco do módulo. Ou

\footnotetext{
${ }^{13}$ Essa visível "facilidade" faz com que as deficiências de aprendizagem vão se acumulando ano a ano, e o nível de ensino abaixando cada vez mais, pois os professores acabam nivelando por baixo seus alunos para poder aprová-los. Esse descaso com os deveres escolares também é reflexo da realidade social brasileira. Se muitos dos homens que representam o poder público não cumprem suas obrigaçôes profissionais, legais e sociais e nem por isso são punidos, alastra-se, inconscientemente, um sentimento de falta de responsabilidade com as obrigaçōes em geral, de impunidade. Parece que virou regra o descumprimento das nossas obrigaçōes, sejam elas sociais, legais ou didáticas, como é o nosso caso.
} 
seja, pretendíamos, dessa maneira, ativar um gesto didático de regulação diagnóstica. Abaixo, trazemos alguns relatórios escritos nesse dia: ${ }^{14}$

A1 - "Aprendi que quando você tem uma reclamação, você tem que agir, não ficar calado(a) e não fazer nada. Você pode escrever uma carta ou conversar que tudo vai se resolver."

A2 - "Hoje eu aprendi, através do quadro púlpito, altas horas, que a gente não deve ficar calado, temos que agir, reclamar, conversar e até fazer um abaixo assinado."

A3 - "Hoje aprendi um pouco do púlpito. Os meus colegas eles protestaram, pois eles fiseram uma reclamação do que eles acham que é errado. Esse foi um geito que eu entendi.”

No relatório dos três alunos, aparece o termo reclamação/reclamar, o que mostra, antes de qualquer coisa, que eles começaram a se inserir na temática do projeto. Os alunos 1 e 2 mobilizaram modalizadores deônticos (BRONCKART, 2003, p. 331) da ordem das obrigaçôes sociais: "você deve agir", "a gente não deve ficar calado", "temos que agir, reclamar...", mostrando que interpretaram a ação de reclamar como uma "obrigação social", o que demonstra que conseguiram apreender a esfera socialna qual a ação de reclamar está inserida, uma vez que reclamar é um ato de cidadania, de pertencimento a uma comunidade social.

Seguindo outra direção discursiva, o aluno 1 também aciona um modalizador lógico (BRONCKART, 2003, p. 330) da ordem do provável "você pode escrever uma carta ou conversar". Nesse caso, é possível perceber que o aluno entendeu que esse dever social de reclamar tem várias possibilidades de realização discursiva, dando como exemplos a "carta" e a "conversa". Esses dois gêneros foram apontados pelos alunos na atividade feita com o professor na lousa, o que demonstra que a intervenção do professor, neste módulo, foi o que determinou o aprendizado do aluno - ele não partiu de um conhecimento prévio. $\mathrm{O}$ mesmo aluno, ao usar uma modalização lógica da ordem dos fatos atestados - "tudo vai se resolver" -, mostra que interpretou erroneamente a funcionalidade discursiva desses gêneros. Isso porque, a

${ }^{14}$ Para efeito de análise, compilamos, aleatoriamente, alguns cadernos de alunos. As transcriçôes estão de acordo com a grafia apresentada. A nossa intenção, nesta etapa analítica do artigo, é articular o agir do professor, os instrumentos e objetos de ensino, e o aprendizado do aluno. Por isso a necessidade de colocar em evidência também a recepção, pelos alunos, do trabalho didático, fruto da intervenção da nossa pesquisa. 
reclamação, em si, não garante uma solução para o problema, ela é um instrumento que "possibilita" a resolução, mas não a determina. Talvez o aluno estivesse influenciado pela fala da professora ao mostrar como a forma que representamos a situação comunicativa - quem é o destinatário, os objetivos da comunicação, etc. - e textualizamos - mais formalmente, usando vocabulários adequados - "pode" garantir o sucesso da nossa reclamação, mas não garanti-la. Esse é um ponto que precisou ser retomado na institucionalização da carta de reclamação, nos demais módulos.

$\mathrm{O}$ aluno 3, embora parecendo ainda não se sentir inserido no projeto, pois relata as reclamaçóes que os "outros" fizeram (voz de personagens: os colegas da classe), coloca um ponto importantíssimo para o sucesso da SD - o fato de precisarmos interpretar algo como digno de ser um problema para ser reclamado: "fiseram (sic) uma reclamação do que eles acham que é errado". Ou seja, é uma necessidade real de comunicação se transformando em motivação para a escrita escolar. Esse módulo foi elaborado justamente pensando em fazer com que a significação social de uma reclamação se transformasse efetivamente em sentido para a escrita em situação escolar.

Outro gesto de regulação, próprio da maioria do nosso contexto escolar público, é o "visto" no caderno dos alunos. Esse procedimento gera, a cada final de bimestre, uma nota de participação/disciplina. No entanto, como já ressaltamos, ele traz poucos resultados positivos, pois os alunos que comumente não participam da aula não se "intimidam" com esse procedimento. Para esses alunos, ele não é um gesto motivador para a atividade de ensino. Ele traz resultados apenas para aqueles que realmente estão motivados pelo aprendizado. O aprendizado é o que, realmente, dá sentido para a atividade escolar.

\section{Considerações finais}

Este trabalho buscou destacar a relevância de se analisar o trabalho reall realizado do professor:

A análise do trabalho real ${ }^{15}$ constitui primeiramente um meio de informação sobre o teor das práticas profissionais concretas, permitindo a transformação ou a melhoria destas; constitui também um meio de

\footnotetext{
${ }^{15}$ A citação da autora parece mais contemplar o que Clot (2007) denomina trabalho realizado. Na nossa pesquisa, analisamos, em parte, o trabalho real do professor, quando investigamos as reconcepçôes feitas nas planificações da SD durante o trabalho realizado.
} 
informação sobre o teor das novas ou emergentes formas de atividade e nisto um instrumento suscetível de contribuir para sua definição ou redefinição [...]; constitui, enfim, uma ferramenta suscetível de permitir o acesso às competências e aos saberes profissionais contextualmente elaborados pelos operadores, ao desafio de profissionalização estando primeiramente associado a um desafio de capitalização destes mesmos saberes, em vista de sua transmissão aos pares ou aos formados (BULEA, 2010, p. 28-29).

Essa citação é bastante pertinente, uma vez que mostra a importância da investigação das atividades de trabalho, em especial, do trabalho real/realizado, para profissionalização ${ }^{16}$ das atividades e disseminação de saberes que as envolvem. No âmbito da atividade docente, as pesquisas que focam o trabalho efetivamente realizado pelo professor são essenciais para que tal atividade possa ser compreendida em toda sua complexidade, o que inclui investigaçóes: do agir do professor, dentro e fora da sala de aula (na planificação das tarefas, por exemplo); dos seus gestos didáticos (aprendidos? Imitados? Adaptados? Criados?); dos gêneros de atividade mobilizados; da realização das tarefas (do professor e dos alunos); das representações do trabalho docente etc.

Outro ponto relevante das pesquisas que focam o trabalho do professor, como o artigo em questão, diz respeito à necessidade de "disseminação" dos saberes que envolvem a atividade docente. A sala de aula, vista sob o ponto de vista de um locus de trabalho, é um lugar, quase sempre, fechado no agir de um único profissional: o professor. O seu trabalho é individual e, normalmente, não é partilhado com os seus pares. O professor é um trabalhador que age sozinho e, na maioria dos casos, inicia sua vida profissional "imitando" ou "adaptando" os gestos didáticos dos seus antigos professores (TARDIF, 2006) ou se contrapondo a eles, tentando agir de modo não "tradicional". Entretanto, ele apenas cria o seu estilo profissional na prática, no seu trabalho diário, a partir de erros e acertos, de adaptaçõos acertadas e frustradas, de sucessos e insucessos, pois o seu "treinamento" é feito a partir da inserção direta na atividade de trabalho. Não há um período de aprendizado anterior à prática, no qual o sujeito possa receber orientaçóes dos pares mais experientes, discutir estratégias pedagógicas, prever e solucionar possíveis problemas relacionados à sala de aula etc.

\footnotetext{
${ }^{16} \mathrm{O}$ termo profissionalização é tomado aqui em um sentido mais abrangente, focado na qualificação e no desenvolvimento de uma profissão - e não como simples ato de treinamento/formação de trabalhadores para exercer certa profissão.
} 
No Brasil, infelizmente, os estágios obrigatórios das Licenciaturas, normalmente, não cumprem tal função, ou cumprem de maneira insatisfatória (HILA, 2011; BUENO, 2007). Dessa forma, é papel essencial das pesquisas de formação docente analisar, compreender e sistematizar os saberes que fundamentam o agir do professor, para que esses, depois de sistematizados, possam ser trabalhados nos cursos de graduação e, assim, sirvam, não apenas para mostrar um panorama atualizado do trabalho docente, mas, sobretudo, para que a atividade do professor possa ser discutida, problematizada e, com isso, se enriquecer a partir de uma visão científica e, assim, se profissionalizar.

No caso específico dos gestos didáticos, entendemos que esses precisam ser objeto de ensino nos cursos de formação inicial e continuada, mas não com o objetivo de "engessá-los" a formas "certas" ou "erradas", mas de colocá-los em evidência como foco de debates, como um elemento essencial do trabalho docente. Para isso, pesquisas como a apresentada nesse trabalho são essenciais para "descortinar" a atividade docente e colocar em evidência os gestos didáticos específicos que emergem do métier do professor, durante a mobilização dos gestos didáticos fundadores.

\section{Referências}

AEBY-DAGHÉ, Sandrine; DOLZ, Joaquim. Des gestes didactiques fondateurs aux gestes spécifiques à l'enseignement-apprentissage du texte d'opinion. In: BUCHETON, Dominique; DEZUTTER, Olivier (Org.). Le développement des gestes professionnels dans l'enseignement du français: un défi pour la recherche et la formation. Bruxelas: De Boeck, 2008. p. 83-105.

AMIGUES, René. Trabalho do professor e trabalho de ensino. In: MACHADO, Anna Rachel (Org.). O ensino como trabalho: uma abordagem discursiva. Londrina: Eduel, 2004. p. 35-53.

BAKHTIN, Mikhail; VOLOCHINOV, Valentin Nikolaevich. Marxismo e filosofia da linguagem. Trad. Michel lahud e Yara F. Vieira. 3.ed. São Paulo, HUCITEC, 1986.

BORTONI-RICARDO, Stela Maris; PEREIRA, Ana Dilma de A. Formação continuada de professores e pesquisa etnográfica colaborativa. MOARA, Estudos Linguísticos. Revista da Pós-Graduação em Letras da UFPA, Belém, n. 26, p. 149-162, ago./dez. 2006.

BRONCKART, Jean-Paul. Atividade de linguagem, textos e discursos: por um interacionismo sócio-discursivo. Trad. Anna Rachel Machado e Péricles Cunha. 2. reimpressão. São Paulo: EDUC, 2003. 
BRONCKART, Jean-Paul. Atividade de linguagem, discurso e desenvolvimento humano. Org. Anna Rachel Machado e Maria de Lourdes Meireles Matencio. Trad. Anna Rachel Machado et al. Campinas/SP: Mercado das Letras, 2006.

BRONCKART, Jean-Paul. O agir nos discursos: das concepçôes teóricas às concepções dos trabalhadores. Trad. Anna Rachel Machado. Campinas: Mercado das Letras, 2008.

BUENO, Luzia. A construção de representações sobre o trabalho docente: o papel do estágio. São Paulo, 2007. Tese (Doutorado em Linguística Aplicada e Estudos da Linguagem) - Pontifícia Universidade Católica de São Paulo, São Paulo, 2007. BULEA, Ecaterina. Linguagem e efeitos desenvolvimentais da interpretação da atividade. Trad. Eulália Vera F. Leurquin e Lena Lúcia E. R. Figueiredo. Campinas: Mercado das Letras, 2010.

CHEVALLARD, Yves. Les processus de transposition didactique et leur théorisation. 1984. Disponível em: <http://yves.chevallard.free.fr/spip/spip/article.php3?id_ article $=114>$. Acesso em 17 jan. 2011.

CLOT, Yves. A função psicológica do trabalho. Trad. Adail Sobral. 2.ed. Petrópolis/ RJ: Vozes, 2007.

CRISTOVÃO, Vera Lúcia Lopes; ABREU-TARDELli, Lília S. (Org.) Linguagem e educação: o trabalho do professor em uma nova perspectiva. Campinas: Mercado das Letras, 2009.

DOLZ, Joaquim. De que adianta conhecer o código, se não entende o texto? Entrevista realizada por Luiz Henrique Gurgel para o portal das Olimpíadas de Língua Portuguesa: Escrevendo o Futuro, 2010. Disponível em: <www.escrevendo. cenpec.org.br>. Acesso em: 25 maio 2010.

DOLZ, Joaquim; GAGNON, Roxane; CANELAS-TREVISI, Sandra. Cartes conceptuelles dês objets d'enseignement. In: SCHNEUWLY, Bernard; DOLZ, Joaquim (Org.). Des objets enseignés en classe de français. Renes: Presses Universitaries Rennes, 2009. p. 65-74.

DOLZ, Joaquim; NOVERRRAZ, Michèle; SCHNEUWLY, Bernard. Seqüências didáticas para o oral e a escrita: apresentação de um procedimento. In: SCHNEUWLY. Bernard; DOLZ, Joaquim (org.). Gêneros orais e escritos na escola. Trad. Roxane Rojo e Glaís Sales Cordeiro. Campinas: Mercado de Letras, 2004. p. 95-128.

FAÏTA, Daniel. Gêneros de discurso, gêneros de atividade, análise do professor. In: MACHADO, Anna Rachel (Org.). O ensino como trabalho: uma abordagem discursiva. Londrina: Eduel, 2004. p. 55-80. 
FILLIETTAZ, Laurent. As contribuiçōes de uma abordagem praxeológica do discurso para a análise do trabalho do professor: o enquadramento das atividades em aula. $O$ ensino como trabalho: uma abordagem discursiva. Londrina: Eduel, 2004. p. 199-235.

GROSJEAN, Michèle; LACOSTE, Michèle. Communication et intelligence collective: le travail à l'hôpital. Paris: Presses Universitaires de France, 1999.

HILA, Cláudia Valéria D. Ferramentas curso de formação e sequência didática: contribuiçōes para o processo de internalização no estágio de docência de língua portuguesa. 2011. Tese (Doutorado em Estudos da Linguagem) - Universidade Estadual de Londrina, Londrina, 2004.

LAJOLO, Marisa. Livro didático: um (quase) manual do usuário. Em Aberto, Brasília, ano 16, n. 69, jan./mar. 1996, p. 3-9. Disponível em: <http:// rbep.inep.gov.br/index.php/emaberto/article/viewFile/1033/935>. Acesso em: 10 maio 2010.

LOUSADA, Eliane Golvêa. Entre trabalho prescrito e realizado: um espaço para a emergência do trabalho real do professor. 2006. Tese (Doutorado em Linguística Aplicada) - Pontifícia Universidade Católica de São Paulo, São Paulo, 2006.

LOUSADA, Eliane Golvêa. Análise de textos e discursos em situação de trabalho educacional. Slides do Estudo Avançado ministrado no Programa de Estudos da Linguagem da UEL, 2011.

MACHADO, Anna Rachel. Trabalho prescrito, planificado e realizado na formação de professores: primeiro olhar. In: CRISTOVÃO, Vera Lúcia; ABREUTARDELLI, Lília S. (Org.) Linguagem e educação: o trabalho do professor em uma nova perspectiva. Campinas: Mercado das Letras, 2009. p. 79-99.

MACHADO, Anna Rachel et al. Relações entre linguagem e trabalho educacional: novas perspectivas e métodos no quadro do interacionismo sociodiscursivo. In: CRISTOVÃO, Vera Lúcia; ABREU-TARDELLI, Lília S. (Org.). Linguagem e educação: o trabalho do professor em uma nova perspectiva. Campinas: Mercado das Letras, 2009.

MACHADO, Anna Rachel; BRONCKART, Jean-Paul. (Re-)configurações do trabalho do professor construídas nos e pelos textos: a perspectiva metodológica do grupo ALTER-LAEL. In: CRISTOVÃO, Vera Lúcia; ABREU-TARDELLI, Lília S. (Org.). Linguagem e educação: o trabalho do professor em uma nova perspectiva. Campinas: Mercado das Letras, 2009. p. 31-77.

MACHADO, Anna Rachel; LOUSADA, Eliane. A apropriação de gêneros textuais pelo professor: em direção ao desenvolvimento pessoal e à evolução do "métier". Linguagem em (Dis)curso, Palhoça, SC, v. 10, n. 3, p. 619-633, set./ dez. 2010. 
MACHADO, Anna Rachel; LOUSADA, Eliane; FERREIRA, Anise D'Orange (Org.). O professor e seu trabalho: a linguagem revelando práticas docentes. Campinas: Mercado das Letras, 2011.

NASCIMENTO, Elvira Lopes. A dupla semiotização dos objetos de ensinoaprendizagem: dos gestos didáticos fundadores aos gestos didáticos específicos. Signum: Estudos da Linguagem, Londrina, v. 14, n. 1, p. 421-445, jun. 2011 a. NASCIMENTO, Elvira Lopes. Mediações formativas e apropriação de gêneros textuais. SIMPÓSIO INTERNACIONAL DE GÊNEROS TEXTUAIS SIGET, 6., 2011b, Natal. Anais... Natal: UFRN, 2011b. <Disponível em: http://www.cchla.ufrn.br/visiget/>. Acesso em 22 out. 2011.

NASCIMENTO, Elvira Lopes. Gêneros da atividade, gêneros textuais: repensando a interação em sala de aula. In: (Org.). Gêneros textuais: da didática das línguas aos objetos de ensino. São Carlos: Claraluz, 2009. p. 51-90.

RABARDEL, Pierre. Les Hommes et les technologies: une approche cognitive des instruments contemporains. Paris: Université de Paris 8, 1995. Disponível em:

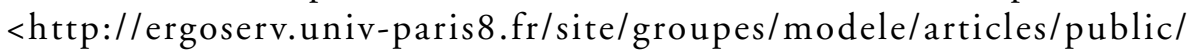
art372105503765426783. pdf>. Acesso em: 05 jan. 2010.

SAUJAT, Frédéric. $\mathrm{O}$ trabalho do professor nas pesquisas em educação: um panorama. In: MACHADO, Anna Rachel (Org.). O ensino como trabalho: uma abordagem discursiva. Londrina: Eduel, 2004. p. 3-34.

SAUJAT, Frédéric. Ergonomie de l'activité enseignante et développement de l'expérience professionnelle: une approche clinique du travail du professeur. 2002. Tese (Doutorado) - Universidade Aix-Marseille, 2002.

SCHNEUWLY, Bernard; DOLZ, Joaquim (Org.). Gêneros orais e escritos na escola. Campinas: Mercado de Letras, 2004.

SOUZA-e-SILVA, Maria Cecília Perez de. O ensino como trabalho. In: MACHADO, Anna Rachel (Org.). O ensino como trabalho: uma abordagem discursiva. Londrina: Eduel, 2004. p. 81-104.

TARDIF, Maurice. Saberes docentes e formação profissional. 6. ed. Petrópolis/RJ: Vozes, 2006.

VIGOTSKI, Lev Semenovich. A formação social da mente. Trad. José Cipolla Neto; Luiz S. M. Barreto; Solange C. Afeche. 7. ed. São Paulo: Martins Fontes, 2008. 